Corrigendum

\title{
Corrigendum to "Road traffic noise, blood pressure and heart rate: Pooled analyses of harmonized data from 88,336 participants” [Environ. Res. 151 (2016) 804-813]
}

\author{
Wilma Zijlema ${ }^{\mathrm{a}, \mathrm{b}, \mathrm{c}, \mathrm{d}, *}$, Yutong Cai ${ }^{\mathrm{e}}$, Dany Doiron ${ }^{\mathrm{f}, \mathrm{g}, \mathrm{h}}$, Stéphane Mbatchou ${ }^{\mathrm{f}}$, Isabel Fortier ${ }^{\mathrm{f}}$, \\ John Gulliver ${ }^{\mathrm{e}}$, Kees de Hoogh ${ }^{\mathrm{e}, \mathrm{g}, \mathrm{h}}$, David Morley, ${ }^{\mathrm{e}}$, Susan Hodgson ${ }^{\mathrm{e}}$, Paul Elliott ${ }^{\mathrm{e}}$, Timothy Key ${ }^{\mathrm{i}}$, \\ Havard Kongsgard ${ }^{j}$, Kristian Hveem ${ }^{j}$, Amadou Gaye ${ }^{\mathrm{k}}$, Paul Burton ${ }^{\mathrm{l}}$, Anna Hansell ${ }^{\mathrm{e}, \mathrm{m}}$, \\ Ronald Stolk ${ }^{\mathrm{a}}$, Judith Rosmalen ${ }^{\mathrm{n}}$ \\ ${ }^{\text {a }}$ University of Groningen, University Medical Center Groningen, Department of Epidemiology, Groningen, The Netherlands \\ b ISGlobal, Centre for Research in Environmental Epidemiology (CREAL), Barcelona, Spain \\ c Universitat Pompeu Fabra (UPF), Barcelona, Spain \\ d CIBER Epidemiología y Salud Pública (CIB ERESP), Madrid, Spain \\ e MRC-PHE Centre for Environment and Health, Imperial College London, London, United Kingdom \\ ${ }^{\mathrm{f}}$ Research Institute of the McGill University Health Centre (RI-MUHC), Montréal, Québec, Canada \\ ${ }^{\mathrm{g}}$ Swiss Tropical and Public Health Institute, Basel, Switzerland \\ h University of Basel, Basel, Switzerland \\ i Cancer Epidemiology Unit, Nuffield Department of Population Health, University of Oxford, Oxford, United Kingdom \\ ${ }^{\mathrm{j}}$ HUNT Research Centre, Department of Public Health and General Practice, Norwegian University of Science and Technology, Levanger, Norway \\ k National Human Genome Research Institute, Metabolic, Cardiovascular and Inflammatory Disease Genomics Branch, Bethesda, USA \\ ${ }^{1}$ School of Social and Community Medicine, University of Bristol, Bristol, United Kingdom \\ m Imperial College Healthcare NHS Trust, London, United Kingdom \\ ${ }^{n}$ University of Groningen, University Medical Center Groningen, Departments of Psychiatry and Internal Medicine, Groningen, The Netherlands
}

The authors regret that the affiliation of author Anna Hansell and present address of author Wilma Zijlema were incorrect. The affiliation of Anna Hansell is MRC-PHE Centre for Environment and Health, Imperial College London, London, United Kingdom, and Imperial
College Healthcare NHS Trust, London, United Kingdom. The present address of Wilma Zijlema is ISGlobal, Centre for Research in Environmental Epidemiology (CREAL), Barcelona, Spain.

\footnotetext{
DOI of original article: http://dx.doi.org/10.1016/j.envres.2016.09.014

* Corresponding author at: ISGlobal, Centre for Research in Environmental Epidemiology (CREAL), Barcelona, Spain.

E-mail address: wilma.zijlema@isglobal.org (W. Zijlema).
} 